\title{
Fontan outcomes: Is being educated as good as being wealthy and healthy?
}

\author{
Yves d'Udekem, MD, PhD, FRACS
}

From the Department of Cardiac Surgery, Royal Children's Hospital, Melbourne, Victoria, Australia; Murdoch Children's Research Institute, Melbourne, Victoria, Australia; and Department of Pediatrics of the University of Melbourne, Melbourne, Victoria, Australia.

The Victorian Government's Operational Infrastructure Support Program supported this research project.

Disclosures: Dr d'Udekem is a consultant for MSD and Actelion and is a National Health and Medical Research Council (NHMRC) Clinical Practitioner Fellow (1082186).

Received for publication Nov 28, 2017; accepted for publication Dec 13, 2017; available ahead of print Jan 10, 2018.

Address for reprints: Yves d'Udekem, MD, PhD, FRACS, Department of Cardiac Surgery, Royal Children's Hospital, Flemington Rd, Parkville, Melbourne, Victoria 3052, Australia (E-mail: yves.dudekem@rch.org.au).

J Thorac Cardiovasc Surg 2018;155:1732-3

$0022-5223 / \$ 36.00$

Copyright $(2) 2017$ by The American Association for Thoracic Surgery

https://doi.org/10.1016/j.jtcvs.2017.12.050

In this issue of the Journal, Karamlou and colleagues ${ }^{1}$ beautifully demonstrated to what extent socioeconomic factors may impact on health parameters of patients born with congenital heart disease and stress the importance of performing more of such detailed studies. This review was inspired by the recently published report of the third cross-sectional study of the Pediatric Heart Network (PHN). This report stipulated that, over 10 years, patients with reported family incomes superior to \$100,000 had a lower risk of death and transplantation. ${ }^{2}$ Karamlou and colleagues detailed the lack of precision with which the socioeconomic parameters were studied in this work and detail the way such study should be conducted. One should remember that this longitudinal study of patients with a Fontan circulation of the PHN was designed to "identify a quantifiable measure of cardiovascular performance that correlates with clinical outcome assessed by a validated, health-related quality of life instrument in children treated with a Fontan procedure." 3 Therefore, this longitudinal study was not designed to accurately assess the impact of socioeconomic factors, and they should therefore not be criticized for the lack of accuracy in this aspect of this study.

But can we nonetheless speculate on their finding?

One can be suspicious that poorer quality of follow-up was not the factor that impaired patients' health. The association between optimal regular follow-up and improved outcomes has been proven in the late survivors of tetralogy of Fallot repair, but is it the same for patients with a Fontan circulation? ${ }^{4}$ Care pathways after Fontan are still unclear, and we cannot be certain today that increased follow-up improves the health of patients with a Fontan circulation. ${ }^{5}$

Even if it cannot be demonstrated in the frame of the PHN study, there is no doubt in my mind that a healthier lifestyle would lead to improved outcomes after Fontan surgery, as Karamlou and colleagues suggested. A worse lifestyle also adversely affects the Fontan circulation. There are only preliminary data pointing to the deleterious impact

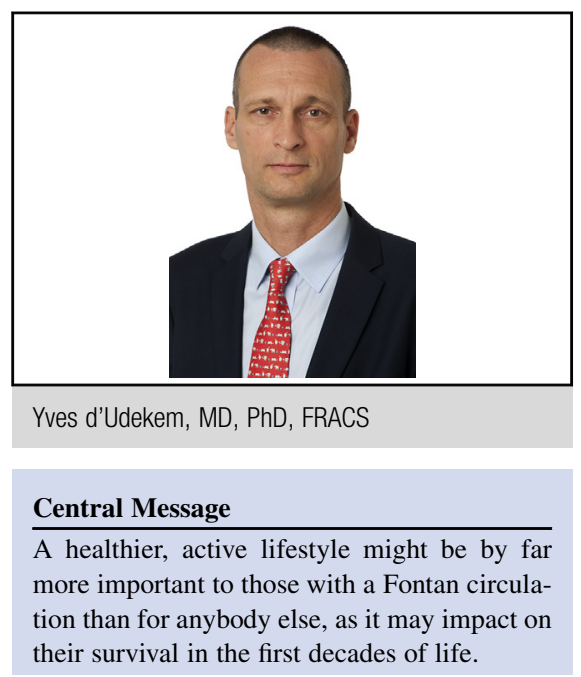

See Article page 1727

of obesity on the outcomes after Fontan, but anecdotal evidence and informal reports points to a dramatic effect. ${ }^{6}$ There is growing evidence that exercise training is beneficial in patients and that increased muscle mass provides increased maximal exercise capacity. We have recently reported that a fraction of the Fontan population have a normal exercise capacity. ${ }^{7}$ Our first impression of these patients with normal exercise capacity is that they were highly educated individuals who practiced frequent physical activity. In this last PHN study, patients with a reduced Child Health Questionnaire physical summary score, reflective of a decreased level of physical activity, had a greater risk of death and transplantation.

There is today an abundance of signs that leading a healthy lifestyle is a very strong determinant of better outcome for patients with a Fontan circulation. We have made fantastic progress in obtaining survival in these patients by refining our indications and improving their care up to the operation. Is it now time that we integrate an education program to achieve a healthier lifestyle into our care pathway for patients surviving with a single ventricle?

\section{References}

1. Karamlou T, Peyvandi S, Federman M, Goff D, Murthy R, Ramkumar S. Resolving the Fontan paradox: addressing socioeconomic and racial disparities in single ventricle patients. J Thorac Cardiovasc Surg. 2018;155:1727-31.

2. Atz AM, Zak V, Mahony L, Uzark K, D'agincourt N, Goldberg DJ, et al. Longitudinal outcomes of patients with single ventricle after the Fontan procedure. J Am Coll Cardiol. 2017;69:2735-44. 
3. Sleeper LA, Anderson P, Hsu DT, Mahony L, McCrindle BW, Roth SJ, et al. Design of a large cross-sectional study to facilitate future clinical trials in children with the Fontan palliation. Am Heart J. 2006;152:427-33.

4. Wray J, Frigiola A, Bull C. Adult Congenital Heart disease Research Network (ACoRN). Loss to specialist follow-up in congenital heart disease; out of sight, out of mind. Heart. 2013;99:485-90.

5. d'Udekem Y, Rychik J. Towards the goal of achieving a normal duration and quality of life after Fontan operation: creation of the International Fontan Interest group (I-FIG), an international collaborative initiative dedicated to improving outcomes. Int J Cardiol. 2017;245:131-4.

6. Martinez SC, Byku M, Novak EL, Cedars AM, Eghtesady P, Ludbrook PA, et al. Increased body mass index is associated with congestive heart failure and mortality in adult Fontan patients. Congenit Heart Dis. 2016;11:71-9.

7. Cordina R, du Plessis K, Tran D, d'Udekem Y. Super-Fontan: is it possible? J Thorac Cardiovasc Surg. 2018;155:1192-4. 